\title{
CONTRIBUIÇÕES DO PENSAMENTO FREIREANO PARA A ESCOLARIZAÇÃO DE MULHERES TRABALHADORAS NA EDUCAÇÃO DE JOVENS E Adultos (EJA)
}

\author{
Ana Cláudia Ferreira Godinho \\ Universidade Federal do Rio Grande do Sul (UFRGS), Porto Alegre, \\ Rio Grande do Sul, Brasil \\ Nagela ApareCida Brandão \\ Ana Catharina Mesquita de Noronha \\ Universidade do Estado de Minas Gerais (UEMG), Belo Horizonte, \\ Minas Gerais, Brasil
}

\begin{abstract}
Resumo: Neste artigo, analisamos as contribuições da educação popular, especialmente do pensamento freireano, para a escolarização de mulheres na Educação de Jovens e adultos (EJA), em especial no que se refere à problematização de suas experiências de trabalho. Apresentamos reflexões produzidas a partir de um estudo de caráter etnográfico, realizado em duas escolas públicas de Belo Horizonte - MG. Os resultados indicam que as experiências das mulheres, inclusive das estudantes sujeitos de pesquisa, são de trabalho precário. Diante disso, a sala de aula de EJA é, para muitas, o único espaço de problematização destas experiências para a compreensão das relações sociais que constituem o trabalho humano. Compreender essas questões pode contribuir para que as mulheres trabalhadoras deixem de atribuir a si mesmas a responsabilidade por todas as condições precárias de trabalho em que vivem e por não terem a escolaridade completa.
\end{abstract}

Palavras-Chave: Educação de Jovens e Adultos. Educação popular. Trabalho. Mulheres. 
INTRODUÇÃO

Este texto analisa as contribuições da educação popular, em especial do pensamento freireano, para a escolarização de mulheres na EJA, no que se refere à problematização de suas experiências de trabalho. Mulheres jovens e adultas têm alcançado maiores níveis de escolaridade nas últimas décadas e são maioria no Ensino Médio, na EJA e no ensino superior, conforme dados do Censo de 2010 (IBGE, 2014).

O predomínio de mulheres em salas de aula de EJA tem motivado pesquisadores/as a buscarem compreender as especificidades destas mulheres. Somente na área da Educação, constam 35 teses e dissertações sobre o tema no banco de teses da Coordenação de Aperfeiçoamento de Pessoal de Nível Superior (CAPES)1. Estes estudos abordam suas trajetórias e histórias de vida, representações, saberes e expectativas em relação à escola. Nesse contexto de produção acadêmica, a pesquisa2 que originou este artigo apresenta reflexões produzidas a partir de um estudo de caráter etnográfico (ANDRÉ, 2004; MATTOS; CASTRO, 2009), em duas escolas públicas de Educação de Jovens e Adultos da cidade de Belo Horizonte - MG, com dados obtidos por meio de observação participante em quatro turmas (duas de alfabetização e duas de segmentos finais do Ensino Fundamental). A análise dos dados baseou-se nas orientações da análise indutiva para trabalhar com os dados de observação de sala de aula, conforme apresentadas por Mattos e Castro (2009). A partir da tematização dos dados gravados, realiza-se a descrição das aulas, de acordo com a recorrência e a "tipicalidade dos fatos ou fenômenos, eventos, ações e falas na sala de aula" (p. 2) e as categorias emergem da interpretação desses dados, daquilo que é aparente nas imagens e transcrições. Esse processo faz parte do que Fontoura (2009) define como tematização: "[...] é a escolha das situações mais relevantes e significativas, em geral extraídas das falas ou das imagens que mais dizem ao pesquisador sobre o assunto escolhido" (p. 39-40).

O texto organiza-se em quatro partes. Na primeira, destacamos algumas concepções da Educação Popular presentes na obra de Paulo Freire que influenciam a Educação de Jovens e Adultos no sentido de contribuir para a formulação de práticas escolares voltadas à emancipação humana. Destacamos a contribuição para o reconhecimento dos sujeitos da EJA como sujeitos de direitos e como protagonistas da História, da Cultura e de experiências e saberes produzidos fora da escola, como base para a problematização e a leitura crítica do mundo e de si mesmos. Com base nessa ideia, procuramos analisar, na segunda parte, as especificidades das mulheres trabalhadoras pouco escolarizadas como um sujeito importante da 
EJA, uma vez que tem sido o público predominante nas salas de aula desta modalidade. Buscamos apresentar as características das experiências de trabalho destas mulheres, com base em dados censitários e nos dados obtidos na pesquisa que realizamos recentemente. Na sequência, apresentamos alguns aspectos sobre o reconhecimento destas experiências de trabalho como objeto de problematização em sala de aula, entendendo-a, em conformidade com as ideias de Paulo Freire (1987; 1989; 2014), como um espaço de rico potencial para a leitura crítica do mundo, o que envolve compreender e analisar as próprias condições de trabalho e de vida e a si mesmas, enquanto trabalhadoras que (re) produzem a vida imersas nesse contexto. Por fim, as considerações finais retomam alguns aspectos sobre a problematização das experiências de trabalho das mulheres estudantes de EJA para ressaltar as contribuições que a Educação Popular tem a dar no sentido de produzir práticas educativas que reconheçam as experiências e os saberes não escolares dos/as estudantes desta modalidade e, a partir deste reconhecimento, estabeleçam diálogo com os saberes escolares que configuram o currículo da EJA.

Contribuições da Educação Popular para a Educação de Jovens e AdulTOS: O RECONHECIMENTO DOS SUJEITOS DA EJA EM SUA DIVERSIDADE E EM SUA ESPECIFICIDADE

A Educação de Jovens e Adultos é uma modalidade da educação básica que se pauta em muitos princípios e concepções da Educação Popular. A referência às experiências dos movimentos de cultura e de educação popular dos anos 1950 e 1960 é constante nas propostas educativas desta modalidade desde os projetos de educação de trabalhadores dos anos 1990, desenvolvidas em espaços escolares, assim como a experiência de gestão vivida por Paulo Freire na Secretaria Municipal de Educação de São Paulo. Nesse contexto, educadores/as e pesquisadores/as da área produziram uma ampla discussão sobre a possibilidade de que a educação popular orientasse o trabalho realizado na escola pública.

Esse debate contribuiu para tensionar as práticas de escolarização deste público, que eram majoritariamente assistencialistas, compensatórias e infantilizadoras, visto que eram baseadas em preconceitos contra o/a adulto/a analfabeto/a. A esse respeito, Galvão e Di Pierro (2007) analisam as visões preconceituosas sobre os sujeitos da EJA, presentes no debate político sobre o direito ao voto pelo/a adulto/a analfabeto, em meados do século XX e até hoje reproduzidas pelos meios de comunicação. As autoras mostram como pessoas jovens e adultas analfabetas eram e são retratadas 
de modo pejorativo, como incapazes, ignorantes e culpadas pelos problemas e desigualdades sociais do país. Tais retratos baseiam-se na ideia de que a escola é a única fonte de desenvolvimento intelectual e de aprendizado, desconsiderando os saberes produzidos pelos grupos populares em espaços não escolares. Reconhecer as diversas experiências humanas e a cultura popular como fonte de aprendizado e de produção de saberes foi uma das contribuições da Educação Popular e, em especial, da obra de Paulo Freire (1979; 1987; 1989), com base nas experiências dos círculos de cultura, para que até hoje possamos elaborar práticas escolares que se oponham ao preconceito contra a pessoa analfabeta, presente não só nos meios de comunicação, como analisaram Galvão e Di Pierro, mas também em salas de aula de EJA, em que encontramos educadores/as e gestores/as que reproduzem a lógica da suplência, do assistencialismo e da infantilização dos/as estudantes.

As experiências dos círculos de cultura, que inspiraram as primeiras obras de Paulo Freire, possibilitaram a criação de um método de alfabetização de adultos que rompia com as práticas existentes, baseadas em preconceitos amplamente disseminados desde o início do século XX, em que os analfabetos/as eram vistos como ignorantes, incapazes, imaturos e culpados pelos problemas econômicos e sociais do país, como retratam Galvão e Di Pierro (2007), o que justificou a proibição do voto do analfabeto até 1985. Isso permitiu questionar o estereótipo do analfabeto e propor outra concepção de sujeito, que vinculava o/a adulto/a analfabeto/a a experiências e saberes constituídos nas culturas populares. Não caberia, portanto, a estigmatização do analfabeto como uma pessoa desprovida de saberes, mas, sim, uma pessoa cujos saberes são atravessados pela classe social - o que hoje compreendemos ser indissociável de gênero e raça.

Esse reconhecimento dos/as adultos/as analfabetos/as como sujeitos da história, com saberes e experiências de classe, pode ser considerado como uma das grandes contribuições do pensamento freireano para a Educação de Jovens e Adultos. Tanto os projetos educativos desenvolvidos por redes públicas de ensino desde a redemocratização, como o Movimento de Alfabetização de Jovens e Adultos (MOVA) do Estado de São Paulo e do Rio Grande Sul, o Sistema de Educação de Jovens e Adultos (SEJA) e outros; quanto os estudos acadêmicos nesta área evidenciam o que Di Pierro (2005) chamou de "descoberta da diversidade", ou seja, o reconhecimento e o interesse pela diversidade sociocultural dos sujeitos da EJA e suas demandas específicas no que concerne ao seu processo de escolarização.

Desse modo, a Educação de Jovens e Adultos teve uma importante reconfiguração desde a promulgação da Lei de Diretrizes e Bases da Educação 
Nacional no 9394, de 20 de dezembro de 1996. A substituição do ensino supletivo pela Educação de Jovens e Adultos, compreendida como modalidade da Educação Básica - e não mais como uma adaptação do ensino de crianças para outro público -, contribuiu para a configuração da EJA como um campo específico das políticas públicas (DI PIERRO, 2005), bem como de estudos acadêmicos e de formação de educadores/as. Neste sentido, é inegável o avanço da Educação de Jovens e Adultos no Brasil e, como bem aponta Arroyo (2011), " a configuração da EJA como um campo específico de responsabilidade pública do Estado" (p. 20). Conforme o autor, embora a EJA ainda tenha traços de indefinição, improvisação, voluntarismo, apelo a campanhas emergenciais e focalizadas, por outro lado, algumas experiências sinalizavam para sua potencial reconfiguração nos últimos anos: a crescente atuação das universidades no desenvolvimento de ações de extensão, ensino e pesquisas voltadas para a educação de jovens e adultos; a criação de espaços no interior do estado voltados para a discussão e implementação de políticas voltadas à especificidade da EJA; a criação de estruturas específicas para EJA nas secretarias municipais e estaduais de educação; a participação crescente de vários setores da sociedade civil organizada na proposição de projetos ao público da EJA, não mais com formato de campanhas ou ações assistencialistas, mas com maior profissionalismo e sensibilidade para com os direitos desse público.

Este contexto possibilitou à escolarização de jovens e adultos o resgate de princípios caros à Educação Popular, de reconhecimento e valorização de experiências e saberes dos/as estudantes com vistas ao desenvolvimento de processos educativos emancipatórios dentro e fora da escola. A afirmação dos/ as estudantes da EJA como sujeitos de direitos conduz a pensar na escola como espaço de exercício da democracia, em que homens e mulheres não encontrem ali a reprodução de preconceitos contra jovens e adultos dos grupos populares, historicamente construídos em discursos oficiais sobre o analfabetismo e a educação de adultos; mas, ao contrário, encontrem na escola um espaço de estudo e problematização de suas experiências de vida e de trabalho como fontes de histórias, culturas e saberes.

Nessa direção, Freire $(1987 ; 1989 ; 2014)$ afirma a indissociabilidade entre a leitura de mundo e a leitura da palavra, em que a experiência dos grupos populares torna as palavras "grávidas de mundo". Pautada por essas concepções de sujeito e saber, a educação popular pressupõe o diálogo entre sujeitos mediado pelo conhecimento. E este não é somente o conhecimento acumulado pela humanidade e sistematizado em currículos escolares, mas também o conhecimento produzido no cotidiano, nas experiências diversas de vida e de luta pela garantia de seus direitos, protagonizadas pelos grupos populares. Nas palavras de Freire (2014): 
Dessa forma são tão importantes para a formação dos grupos populares certos conteúdos que o educador Ihes deve ensinar quanto a análise que eles façam de sua realidade concreta. E ao fazê-lo, devem ir, com a indispensável ajuda do educador, superando o seu saber anterior, de pura experiência feito, por um saber mais crítico, menos ingênuo (p. 34).

O que o autor afirma é uma posição atuante - e não passiva - destes/ as jovens e adultos/as no processo educativo, em sua permanente busca por ser mais, o que pressupõe a busca de saber mais (FREIRE, 1979). Esta é uma importante contribuição para a escolarização das mulheres trabalhadoras, cujas experiências de vida e de trabalho são marcadas historicamente pela negação de sua capacidade de saber mais3. Tal negação é uma forma de desumanização das mulheres, uma vez que nega uma busca intrínseca ao ser humano, segundo Freire (1979), que é a consciência do próprio inacabamento e a necessidade de saber mais para ser mais.

Diante disso, a educação popular permite o enfrentamento desses processos de desumanização das mulheres, e sua escolarização na EJA torna-se um espaço de enfrentamento dos preconceitos contra as mulheres trabalhadoras e de sua afirmação como sujeitos de direitos.

\section{AS MULHERES TRABALHADORAS NA EJA: A EXPERIÊNCIA DE TRABALHO COMO EIXO ARTICULADOR DO CURRÍCULO}

Diante do reconhecimento da diversidade dos sujeitos da EJA e de suas experiências e saberes não escolares, propomos olhar para as mulheres como sujeitos com especificidades, tanto no que diz respeito à negação de seu direito à educação e ao trabalho quanto à luta pela afirmação destes direitos, que envolve questões culturais, econômicas e políticas. $O$ trabalho é uma das categorias centrais porque compreendemos que ele tem um lugar importante na construção do patrimônio de saberes não escolares que estas pessoas mobilizam em seu processo de aprendizagem e, em algumas situações, verbalizam em sala de aula. A esse respeito, Oliveira (2001) afirma que o/a jovem ou adulto/a da EJA é alguém que está:

inserido no mundo do trabalho e das relações interpessoais, de um modo diferente daquele da criança e do adolescente. Traz consigo uma história mais longa (e provavelmente mais complexa) de experiências, conhecimentos acumulados e reflexões sobre o mundo externo, sobre si mesmo e sobre as outras pessoas (p. 18)

Além disso, na configuração desta especificidade cultural dos/as estudantes, o trabalho é um elo articulador do currículo desta modalidade 
educativa. Consideramos que o trabalho é uma prática social constitutiva não só do patrimônio de saberes, mas também da própria identidade destes sujeitos. Estes, conforme Oliveira (2001), não são marcados por uma especificidade etária, pois os jovens e adultos da EJA não são quaisquer jovens ou adultos. O que os aproximam é uma especificidade cultural, que diz respeito, segundo a autora, à condição de não crianças, à exclusão da escola e ao pertencimento a determinados grupos culturais.

Diante disso, pensamos que o trabalho é um dos elementos que aproxima estes grupos, em que se reconhecem homens e mulheres jovens e adultos/as pouco escolarizados/as. Sendo assim, conhecer as experiências de trabalho das estudantes da EJA permite compreender uma parte importante das relações que estas pessoas estabelecem entre saberes escolares e não escolares, pois consideramos que o trabalho, em sua dimensão ontológica, é uma atividade humana central de produção da vida (FRIGOTTO, 2002; TUMOLO, 2005; SAVIANI, 2007). Além disso, compreendemos que o direito ao trabalho é um ponto de aproximação entre os sujeitos da EJA, cujas experiências de trabalho são marcadas pela exploração de sua força de trabalho para acumulação de capital e pela expropriação de seus saberes, bases da relação capital-trabalho do modo de produção capitalista, como analisam Frigotto (2002), Tumolo (2005), Saviani (2007) e outros estudiosos marxistas da área Trabalho e Educação.

Os estudos sobre a participação feminina no mercado de trabalho no Brasil evidenciam o aumento das taxas de ocupação das mulheres nas últimas décadas (BRUSCHINI; LOMBARDI, 2007; BRUSCHINI, 2007; LAVINAS; CORDILHA; CRUZ, 2016). Com base nesse dado, somado aos dados do Instituto Brasileiro de Geografia e Estatística (IBGE, 2014) sobre a elevação da escolaridade das mulheres jovens e adultas nas últimas décadas, poderíamos supor que as mulheres têm encontrado ocupações com melhores remunerações e condições de trabalho e que haveria uma redução das assimetrias entre o trabalho remunerado de homens e mulheres. Entretanto, não é isto que os dados sobre a participação das mulheres no mercado de trabalho têm mostrado, o que indica que o direito à educação que as mulheres têm buscado nas últimas décadas garantiram sua elevação de escolaridade, mas não foram suficientes para a superação das desigualdades entre homens e mulheres no que se refere à garantia do direito ao trabalho.

Apesar da superioridade escolar feminina, pois [...] a população adulta feminina tem maior nível de instrução que a masculina, os resultados no mercado de trabalho não favorecem as mulheres. [...] as áreas gerais de formação nas quais as mulheres de 25 anos ou mais de idade estão em maior proporção, isto 
é, Educação (83,0\%) e Humanidades e Artes (74,2\%), são justamente aquelas que registram os menores rendimentos médios mensais entre as pessoas ocupadas ( $R \$ 1$ 810,50 e $R \$ 2223,90$, respectivamente), independentemente do setor onde essas pessoas trabalhem. Além disso, o rendimento feminino não se iguala ao masculino em nenhuma das áreas gerais, conforme evidencia a razão entre o rendimento das mulheres e o rendimento dos homens. Esse diferencial se mantém mesmo quando a proporção de mulheres se torna equivalente à dos homens, como na área de Ciências Sociais, Negócios e Direito, em que as mulheres recebiam apenas $66,3 \%$ do rendimento dos homens (IBGE, 2014).

Nesse contexto, conhecer as experiências de trabalho de mulheres pouco escolarizadas que frequentam cursos de Educação de Jovens e Adultos tem a intenção de contribuir para a compreensão desses processos de negação e afirmação de direitos das mulheres trabalhadoras; problematizar estas contradições presentes no trabalho no capitalismo, em que o argumento da meritocracia não encontra correspondência na realidade das mulheres trabalhadoras, que permanecem com rendimentos mais baixos que os dos homens tanto no trabalho formal quanto no trabalho informal, conforme Lavinas, Cordilha e Cruz (2016). Além disso, consideramos que tanto o trabalho quanto o gênero são categorias importantes, que influenciam diretamente os modos de vida das estudantes de EJA, o acesso ou a negação de direitos, como educação e trabalho, bem como influenciam a constituição de seus saberes, histórias e identidades.

A presença das mulheres em cursos de EJA pode ser associada ao trabalho precário a que são submetidas as mulheres pouco escolarizadas (GODINHO, 2012; 2015), em especial a partir da globalização. Diante de um trabalho insuficiente para a própria subsistência e da família, as mulheres procuram a escola na esperança de obter a certificação escolar e, com isso, melhores posições no mercado de trabalho. O trabalho, portanto, está diretamente relacionado às motivações para a retomada dos estudos. A este respeito, Hirata (2009; 2001-2002) define o trabalho precário a partir de três indicadores: ausência de proteção social e de direitos sociais; horas reduzidas de trabalho; e níveis baixos de qualificação.

Conforme a autora, a absorção das mulheres pelo mercado de trabalho é feita de modo a agravar o processo de precarização de ocupações, o que afeta mulheres e homens de modos distintos, permitindo compreender a divisão sexual do trabalho (HIRATA; ZARIFIAN, 2009; KERGOAT, 2009). Além disso, o trabalho das mulheres na atualidade sofre um processo de bipolarização, que a autora explica do seguinte modo: 
[...] de um lado, estabelece-se um pólo constituído por mulheres executivas de profissões intelectuais superiores, categorias que se feminizam (médicas, advogadas, juízas, arquitetas, jornalistas, professoras universitárias, pesquisadoras, assalariadas do ramo da publicidade e da arte, etc.); do outro, mulheres que se mantêm nas ocupações tradicionalmente femininas: funcionárias públicas, da saúde, da educação, dos serviços aos particulares, auxiliares de enfermagem, enfermeiras, professoras primárias, profissionais do home care - que atendem pessoas idosas, doentes, crianças, e que fazem o trabalho doméstico como empregadas, faxineiras, etc. (HIRATA, 2009, p. 30)

No Brasil, é no segundo polo que se situam as estudantes de EJA, sujeitos desta pesquisa. Quais experiências de trabalho elas vivem? Como interpretam estas experiências em sala de aula? Encontram na EJA um espaço de problematização das relações sociais que constituem o trabalho ou atribuem a si mesmas a única razão pelas condições precárias das ocupações em que encontram espaço para a venda da sua força de trabalho, sem que a sala de aula seja um espaço de problematização destas leituras de mundo?

\section{A PROBLEMATIZAÇÃO DAS EXPERIÊNCIAS DE TRABALHO DAS MULHERES - CONTRI- BUIÇÕES E DESAFIOS DA EJA}

Diante das experiências de trabalho das mulheres, compreendemos que a escola tenha contribuições importantes a dar no sentido de fazer da escolarização uma experiência de produção de leitura crítica do mundo e de si mesmas, o que inclui pensar sobre as condições sociais, históricas e culturais que influenciam diretamente o seu acesso a direitos fundamentais para uma vida digna, como a educação, o trabalho, a saúde, a cultura, a participação política e outros.

Pensar sobre os sujeitos da EJA, a escola e a educação na perspectiva da Educação Popular, implica superar o ensino compensatório, assistencialista e infantilizador, que até hoje está presente em muitas escolas de EJA. A este respeito, Arroyo (2011) defende que a EJA oriente suas práticas para o reconhecimento das experiências concretas de vida destas pessoas, com destaque para o trabalho, a violência (como forma de segregação dos sujeitos da EJA, sobretudo das juventudes pobres) e os movimentos sociais (como espaços privilegiados de construção de outras identidades, mais positivas que aquelas produzidas e divulgadas pelos meios de comunicação de massa).

Em outro texto, Arroyo (2011) analisa o currículo como algo a ser disputado pelos sujeitos e coletivos populares, a fim de que se incorpore a diversidade cultural dos mesmos em sala de aula e, assim, estes homens e mulheres se reconheçam como sujeitos de histórias, culturas e saberes 
e como sujeitos de direitos. $\mathrm{O}$ autor analisa que estes sujeitos e coletivos populares têm reivindicado políticas públicas afirmativas que reconheçam suas histórias, culturas e saberes; suas identidades étnico-raciais, de gênero, sexualidade; e seu direito a conhecerem a si mesmos como sujeitos de saberes (ARROYO, 2011). Estas reflexões permitem afirmar a escola como um espaço de construção do público como bem comum, pautada pela dialogicidade, a participação social e a emancipação humana ${ }^{4}$.

Inspiradas nessas reflexões buscamos compreender quais eram as experiências de trabalho das mulheres estudantes das escolas de EJA que pesquisamos. $\mathrm{O}$ que encontramos sobre as experiências de trabalho das mulheres: muitas estudantes de EJA tiveram suas primeiras experiências de trabalho na infância, portanto, experiências de trabalho infanto-juvenil tanto no trabalho doméstico remunerado como no trabalho doméstico não remunerado5. As experiências de trabalho em que as mulheres adultas atuavam, no momento do trabalho de campo eram, majoritariamente, de trabalho doméstico seguido de ocupações na área de comércio e serviços, algumas na forma de trabalho informal (vendedora ambulante, por exemplo). Entre as mulheres jovens, identificamos experiências de trabalho na área de comércio e serviços, devido à participação no programa Jovem Aprendiz.

A problematização destas experiências em sala de aula foi frequente na turma de alfabetização de uma das escolas. Situações de observação nos levaram a acompanhar relatos de experiências sobre o trabalho, estimulados e valorizados pela alfabetizadora como relevantes para a abordagem do tema trabalho. A educadora demonstrou interesse em conhecer o trabalho das estudantes e pautar este tema na aula. Desse modo, as mulheres trabalhadoras encontraram na sala de aula um espaço de problematização das próprias experiências, de relato sobre situações cotidianas de trabalho, de exploração, mas também de afirmação de seu valor e sua identidade como trabalhadoras, apesar de toda a desvalorização social sobre suas ocupações - na maioria dos casos, ligadas ao trabalho doméstico.

Na turma de alfabetização da outra escola, no entanto, o trabalho não foi tematizado pela alfabetizadora durante a observação participante. As aulas não consideravam as experiências de trabalho nem de qualquer outra dimensão da vida dos/as estudantes, e as atividades e os materiais didáticos evidenciavam características de suplência e infantilização dos/as estudantes, problemas persistentes na EJA, até hoje sob influência do ensino supletivo e das inúmeras campanhas de alfabetização de adultos promovidas no país. Estes dados sugerem a importância da formação de educadores/as de jovens e adultos para a construção de um currículo que reconheça e valorize as experiências e os saberes não escolares dos/as estudantes de EJA. 
Outra questão que apareceu na mesma turma é bastante conhecida e divulgada nas diversas pesquisas sobre trabalho e EJA. Refere-se à "culpabilização da vítima". Esta estratégia consiste em transformar os fracassos, limitações e exclusões escolares em fatalidades, determinadas por fatores individuais como "incapacidade" para o estudo e/ou outras apreciações negativas dos sujeitos sobre si mesmos ou dos familiares sobre eles. Ainda que os condicionantes históricos e sociais, como a entrada prematura no mercado de trabalho por causa das dificuldades econômicas, estejam presentes nas visões dos trabalhadores e trabalhadoras da EJA sobre a repetência ou abandono da escola, estes aparentemente não são entendidos por eles/ as como estruturais e históricos, mas destino, má sorte. Provavelmente daí decorre o "processo de autoculpabilização" (FERRETI et. al., 2002 apud RUMMERT, 2008). As dificuldades vivenciadas pela turma no processo de aprendizagem eram imputadas única e exclusivamente às limitações dos/ as próprios/as jovens e adultos/as presentes nas observações realizadas. O que mais chamou a atenção foi a recorrente indicação de médicos e de medicamentos entre estudantes incentivada pela professora. As situações de vida e trabalho dos sujeitos não eram problematizadas. As concepções e metodologias de alfabetização não eram questionadas pela professora. Prevalecia um discurso coletivo de que as dificuldades na alfabetização eram decorrentes dos limites cognitivos, reforçando julgamentos negativos de si mesmos, tais como "burro velho não aprende", "minha mãe sempre dizia que eu era a mais fraca lá de casa, a inteligência foi toda pra um irmão meu", "nunca fui boa nos estudos mesmo".

A "invisibilidade" das experiências de trabalho das mulheres permanece nos segmentos finais do Ensino Fundamental. O espaço para a experiência das estudantes é escasso e o livro didático tem grande influência no planejamento curricular, sendo o material utilizado com maior frequência nas aulas. Assim como a experiência de trabalho, as experiências de vida em geral passam a um lugar de "adendo" na sala de aula e o máximo de espaço que têm costuma ser o de "ilustração" do conteúdo programático em estudo naquele dia. Com esta configuração, os tensionamentos entre saberes escolares e não escolares não têm estímulo para acontecer. Mesmo assim, acompanhamos raros episódios em que os/as estudantes questionam-se sobre a relação entre escolaridade e desemprego, que indicam uma descrença na "escola das promessas", conforme analisa Canário (2008). Segundo o autor, as "promessas" da escola moderna - de mobilidade social ascendente e inserção no mercado formal de trabalho - não podem ser cumpridas na atualidade, dando lugar a uma "escola de incertezas" frente a um contexto de desemprego e precarização do trabalho, que gera instabilidade e agravamento das desigualdades sociais. 
Nesse contexto, Canário (2008) propõe que a escola tenha três finalidades: educar pelo trabalho e não para o trabalho, ou seja, não pensar na escola como um espaço de preparação de um trabalhador adaptado às demandas do capital, mas, sim, o trabalho em suas relações sócio-históricas e culturais e em sua dupla dimensão, histórica e ontológica, como discute Frigotto (2002); tornar a escola um espaço de "desenvolvimento do gosto pelo ato intelectual de aprender" (CANÁRIO, 2008, p. 80); e um espaço de exercício efetivo da democracia. Para tanto, o autor propõe que a escola trabalhe em torno de três eixos: o não escolar, a desalienação do trabalho escolar e a relação da escola com um projeto de sociedade.

Estas ideias estão muito afinadas com as proposições da Educação Popular, encontradas em Freire (1987; 1989; 2014), em Brandão (2002), em Arroyo (2007) e outros. Ou seja, estes autores também abordam a necessidade de se pensar sobre o sentido político da escola na construção de uma sociedade que supere as desigualdades sociais e, nesse contexto, superar as formas de trabalho precário existentes no capitalismo implica na busca de novas formas de construção de conhecimento que reconheçam, valorizem e dialoguem com os saberes produzidos pelos sujeitos e coletivos populares. Estas reflexões fazem parte de concepções e práticas construídas pela Educação Popular, que desde os movimentos de alfabetização de adultos e de cultura popular dos anos 1960 até os dias de hoje, constituem a Educação de Jovens e Adultos e subsidiam a análise dos dados encontrados na pesquisa que originou esse artigo.

\section{CONSIDERAÇÕES FINAIS}

Este texto buscou analisar as contribuições da educação popular, em especial do pensamento freireano, para a escolarização de mulheres na EJA, em especial no que se refere à problematização de suas experiências de trabalho.

Os resultados indicam que as experiências destas mulheres são de trabalho precário, em consonância com dados nacionais sobre a participação feminina no mercado de trabalho no Brasil. As experiências de trabalho das estudantes de EJA que participaram da pesquisa são marcadas pela negação de direitos básicos, como o trabalho e a educação, com o predomínio de experiências de trabalho infanto-juvenil e de trabalho doméstico em muitos casos, sem a proteção trabalhista garantida por lei, experiências de trabalho informal e outras características do trabalho precário, conforme definido por Hirata (2002).

Diante disso, consideramos que as principais contribuições que a instituição escolar tem a dar são a ampliação da leitura crítica destas 
experiências e a retomada do sentido político da educação - voltado para o exercício da cidadania, a valorização da vida, o respeito aos direitos humanos e a construção de uma sociedade democrática - em conformidade com as proposições do campo da Educação Popular de Freire (2001; 1987; 1989), Brandão (2002) e Arroyo (2007) acerca do papel da educação de jovens e adultos na problematização e construção de uma leitura crítica da realidade.

Conforme afirmamos no desenvolvimento deste artigo, pensamos que reconhecer as diversas experiências humanas e a cultura popular como fonte de aprendizado e de saberes foi uma das grandes contribuições do pensamento freireano para que até hoje possamos elaborar práticas escolares antagônicas ao preconceito contra a pessoa analfabeta, ainda reproduzido em algumas salas de aula de EJA, em que persistem a lógica da suplência, do assistencialismo e da infantilização dos/as estudantes. A valorização dos saberes de experiência feitos e a afirmação dos sujeitos da EJA como sujeitos da História, da Cultura e da Política são algumas das contribuições da obra de Paulo Freire para a elaboração de propostas de EJA na perspectiva da Educação Popular após a promulgação da LDB9394/96.

Na pesquisa que originou este artigo, encontramos muitas mulheres estudantes de EJA que atribuem a si mesmas toda a responsabilidade pelas condições precárias de trabalho em que viveram e vivem e culpabilizamse por não terem a escolaridade básica completa. Consideram a falta da certificação escolar a principal ou mesmo a única causa de suas experiências de trabalho precário.

Diante disso, a sala de aula de EJA é, para muitas, o único espaço de problematização destas experiências para a compreensão das relações sociais que constituem o trabalho humano, inclusive as relações sociais de sexo. Para problematizar estas experiências, compreendemos ser necessário conhecê-las, narrá-las e discuti-las com educadores/as e pesquisadores/as da área. Desse modo, pensamos contribuir para a escolarização de jovens e adultos, em especial no que diz respeito à construção de práticas educativas que reconheçam as experiências e os saberes não escolares dos/as estudantes desta modalidade e, a partir deste reconhecimento, estabeleçam diálogo com os saberes escolares que configuram o currículo da EJA, em consonância com as concepções e proposições estudadas na obra de Paulo Freire. 


\section{CONTRIBUTIONS OF FREIRETHINKING FORTHE INSTRUCTION OF WOMEN WORKERS IN THE EDUCATION FOR YOUNG PEOPLE AND ADULTS PROGRAM (EJA)}

ABSTRACT: In this article, we analyze the contributions of Freire thinking for the instruction of women in the in the education for young people and adults program (eja) , specifically regarding an awareness of their own working experiences. We present some reflections drawn from an ethnographic study done in two public schools of Belo Horizonte, Minas Gerais. The results show that the experiences of these women, including the subjects of this study, are of precarious working conditions. Therefore, the young and adult education environment is the only space that allows a reflection upon these experiences in order to understand the social relations that constitute human labor. A better understanding of these problems can contribute for these women workers to stop blaming themselves for the precarious conditions in which they have lived so far, and to stop feeling guilty for not having finished their basic education.

KEYWORDS: Youth and adults education. Popular education. Work. Women.

\section{CONTRIBUCIONES DEL PENSAMIENTO DE FREIRE PARA LA ESCOLARIZACIÓN DE MUJERES TRABAJADORAS EN LA EDUCACIÓN DE JÓVENES Y ADULTOS (EJA)}

RESUMEN: En este artículo, analisamos las contribuciones de la educación popular, especialmente del pensamento freireano, para la escolarización de mujeres en la Educación de Jóvenes y Adultos (EJA), en especial en lo que se refiere a la problematización de sus experiencias de trabajo. Presentamos reflexiones surgidas a partir de un estudio de carácter etnográfico, desarrollado en dos escuelas públicas de Belo Horizonte - MG. Los resultados indican que las experiencias de las mujeres, inclusive de las estudiantes sujetos de la investigación, son de trabajo precario. Dentro de esa perspectiva, la sala de clase de la EJA es, para muchas de ellas, el único espacio de problematización de esas experiencias para la comprensión de las relaciones sociales que constituyen el trabajo humano. Comprender esas cuestiones puede contribuir para que las mujeres trabajadoras dejen de atribuirse la responsabilidad por lo que ha motivado todas las condiciones precarias de trabajo en que viven y por no tener la escolaridad completa.

Palabras Clave: Educación de Jóvenes y Adultos. Educación popular. Trabajo. Mujeres.

\section{NOTAS}

1) Consulta em 21 out. 2016.

2) Agradecemos o apoio da FAPEMIG pela bolsa concedida (BIP-00015-14) e o auxílio do CNPq - Processo 472563/2013-0. 
3) A respeito, o livro de Wollstonecraft (2016), publicado em 1792 e somente lançado no Brasil em 2016 é exemplar na análise dos argumentos apresentados por Rousseau em relação à educação das mulheres, representadas por Sofia, cujo único dever, na visão do filósofo, seria tornar-se "agradável ao seu mestre - sendo este o grande fim de sua existência" (WOLLSTONECRAFT, 2016, p. 107).

4) Reconstruir o espaço público voltado para o bem comum é, conforme Streck (2006), o tema gerador do contexto atual, em que novos elementos requerem da educação popular novas saídas para o que o autor chama de labirinto latino-americano, referindo-se à necessidade de encontrar saídas para as desigualdades sociais, econômicas e políticas denunciadas e combatidas pela Educação Popular desde sua origem.

5) Trabalho doméstico não remunerado é compreendido como o conjunto de afazeres realizados no núcleo familiar, relacionados à organização e ao cuidado.

\section{REFERÊNCIAS}

ANDRÉ, M. Etnografia da prática escolar. 11. ed. São Paulo: Papirus, 2004.

ARROYO, M. Educação de jovens-adultos: um campo de direitos e de responsabilidade pública. In: SOARES, L. et al (Org.) Diálogos na Educação de Jovens e Adultos. 2. ed. Belo Horizonte: Autêntica, 2007.

. Currículo: território em disputa. Petrópolis: Vozes, 2011.

BRANDÃO, C R. O sentido do saber. In: A educação como cultura. Campinas, São Paulo: Mercado de Letras, 2002.

BRASIL. Lei de Diretrizes e Bases da Educação Nacional n. 9.394 de 20 de dezembro de 1996. Disponível em: <http://www.planalto.gov.br/ccivil_03/leis/l9394.htm>. Acesso em: 09 mar. 2013.

BRUSCHINI, M. C. Trabalho e Gênero no Brasil nos Últimos Dez Anos. Cadernos de Pesquisa, São Paulo, v. 37, n. 132, p. 537-572, set./dez. 2007.

BRUSCHINI, M. C.; LOMBARDI, M. R. Trabalho, educação e rendimentos das mulheres no Brasil em anos recentes. In: HIRATA, H.; SEGNINI, L. (Org.) Organização, Trabalho e Gênero. São Paulo: Editora Senac, 2007.

CANÁRIO, R. A escola das "promessas" às "incertezas". Educação Unisinos, São Leopoldo, RS, v. 12, n. 2, p. 73-81, maio/ago. 2008.

DAYRELL, J. A escola como espaço sócio-cultural. In: Múltiplos Olhares sobre Educação e Cultura. Belo Horizonte: Ed. UFMG, 1996.

DI PIERRO, M. C. Notas sobre a redefinição da identidade e das políticas públicas de educação de jovens e adultos no Brasil. Cadernos CEDES, Campinas, v. 26, n. 92, 2005.

FAVERO, O.; FREITAS, M. A Educação de Adultos e Jovens e Adultos: um olhar sobre o passado e o presente. Revista Inter-Ação, Goiânia, v. 36, n. 2, p. 365-392, dez. 2011. 
Disponível em: <https://www.revistas.ufg.br/interacao/article/view/16712>. Acesso em: 17 out. 2016.

FONTOURA, H. A. Revisitando dados e refletindo sobre o uso do vídeo em etnografia. In: MATTOS, C. L. G.; FONTOURA, H. A. Etnografia e Educação: relatos de pesquisa. Rio de Janeiro: EdUERJ, 2009. (Série Pesquisa em Educação/Cultura Escolar).

FREIRE, Paulo. Educação e Mudança. Rio de Janeiro: Paz e Terra, 1979.

. Pedagogia do Oprimido. 17. ed. Rio de Janeiro: Paz e Terra, 1987.

. A importância do ato de ler em três artigos que se complementam. 23. ed. Rio de Janeiro: Paz e Terra, 1989.

. Educação de Adultos Hoje. Algumas reflexões. In:FREIRE, A. M. A. (Org.) Política e Educação. Rio de Janeiro/São Paulo: Paz e Terra, 2014.

FRIGOTTO, G. A dupla face do trabalho: criação e destruição da vida. In:

CIAVATTA, M. (Org.). A Experiência do Trabalho e a Educação Básica. Rio de Janeiro: DP\&A, 2002. p. 11-27.

GALVÃO, A. M; DI PIERRO, M. C. Preconceito contra o analfabeto. São Paulo: Cortez, 2007.

;SOARES, L. História da alfabetização de adultos no Brasil. In: ALBUQUERQUE, E. B. C; LEAL, T. F (Org.). Alfabetização de Jovens e Adultos em uma perspectiva de letramento. Belo Horizonte: Autêntica, 2010.

GODINHO, A. C. F. Experiência de trabalho de mulheres estudantes do PROEJA. In: Reunião da APNPED, 37, 2015. Anais... Florianópolis, 2015.

A experiência escolar de mulheres na Educação Profissional Integrada à EJA: relações de saber em sala de aula. 2012. 280 f. Tese (Doutorado em Educação) - Programa de Pós-Graduação em Educação, Centro de Educação, Universidade do Vale do Rio dos Sinos, 2012.

HIRATA, H. Flexibilidade, trabalho e gênero. In: HIRATA, H.; SEGNINI, L. (Org.) Organização, Trabalho e Gênero. São Paulo: Editora Senac, 2007.

A precarização e a divisão internacional e sexual do trabalho. Sociologias, Porto Alegre, ano 11, n. 21, p. 24-41, jan./jul. 2009.

. Globalização e divisão sexual do trabalho. Cadernos Pagu, Campinas, SP, n. 17-18, p. 139-156, 2001-2002.

; KERGOAT, D. Novas configurações da divisão sexual do trabalho. Cadernos de Pesquisa, São Luís, MA, v. 37, n. 132, p. 595-609, set./dez. 2007.

;ZARIFIAN, P.Trabalho. In: HIRATA, H. et al (Org.). Dicionário Crítico do Feminismo. São Paulo: Ed. da UNESP, 2009.

IBGE. Estatísticas de Gênero - uma análise dos resultados do Censo 2010. Rio de Janeiro: IBGE, 2014. 
OLIVEIRA, M.K. Jovens e adultos como sujeitos de conhecimento e aprendizagem. In RIBEIRO,V.M.(Org.). Educação de Jovens e adultos. São Paulo: Ação Educativa, 2001.p.15-43. KERGOAT, D. Divisão sexual do trabalho e relações sociais de sexo. In: HIRATA, H. et al (Org.). Dicionário Crítico do Feminismo. São Paulo: Ed. da UNESP, 2009.

LAVINAS, L.; CORDILHA, A. C.; CRUZ, G. F. Assimetrias de gênero no trabalho no Brasil: rumos da formalização. In: ABREU, A. R. de P.; HIRATA, H.; LOMBARDI, M. R. (Org.). Gênero e Trabalho no Brasil e na França: perspectivas interseccionais. São Paulo: Boitempo Editorial, 2016.

MATTOS, C. Estudos etnográficos da educação: uma revisão de tendências no Brasil. Educação em foco, Juiz de Fora, MG, v. 11, n. 1, p. 39-58, mar./ago. 2006.

; CASTRO, P. A. de. Espaços, Tempos, Sujeitos: uma análise etnográfica dos saberes produzidos em sala de aula. Teias, Rio de Janeiro, v. 10, p. 1-11, 2009.

OLIVEIRA, M. K. Jovens e adultos como sujeitos de conhecimento e aprendizagem. In: RIBEIRO, V. M (Org.). Educação de Jovens e Adultos: Novos leitores, novas leituras. São Paulo: Mercado de Letras, Ação Educativa, 2001.

RIBEIRO, V. M.; JOIA, O.; DI PIERRO, M. C. Visões da Educação de Jovens e Adultos no Brasil. Cadernos Cedes, Campinas, SP, n. 55, p. 58-77, nov. 2001.

RUMMERT, S. M. A "marca social" da Educação de Jovens e Adultos Trabalhadores. Revista Trabalho e Educação, Belo Horizonte, v. 17, n. 3, set./dez. 2008.

SAVIANI, D. Trabalho e Educação - Fundamentos ontológicos e históricos. Revista Brasileira de Educação, Rio de Janeiro, v. 12, n. 34, jan./abr. 2007.

STRECK, D. Educação Popular e a (re)construção do público. Há fogo sob as brasas? Revista Brasileira de Educação, v. 11, n. 32, maio-ago. 2006.

TUMOLO, P. S. O trabalho na forma social do capital e o trabalho como princípio educativo: uma articulação possível? Educação e Sociedade, Campinas, SP, v. 26, n. 90, p. 239-265, jan./abr. 2005.

WOLLSTONECRAFT, M. Reivindicação dos Direitos da Mulher. São Paulo: Boitempo, 2016.

Ana ClÁudia Ferreira Godinho: Doutora em Educação pela Unisinos. Professora adjunta da Universidade Federal do Rio Grande do Sul (UFRGS) e professora do curso de mestrado em Educação da Universidade do Estado de Minas Gerais (PPGE/FaE/UEMG).

E-mail: anaclaudia.sodinho@gmail.com 
Nagela Aparecida Brandão: Doutora em Educação pela Universidade Federal de Minas Gerais (UFMG). Professora da Faculdade de Educação da Universidade do Estado de Minas Gerais (UEMG).

E-mail: nagelabrandao@yahoo.com.br

Ana Catharina Mesquita de Noronha: Doutora em Educação pela Universidade Federal de Minas Gerais (UFMG). Professora da Faculdade de Educação da Universidade do Estado de Minas Gerais (UEMG).

E-mail:ana.catharina@uol.com.br 